\title{
Management of Incoordinate Uterine Action under Continuous Epidural Analgesia
}

\author{
DONALD D. MOIR,* M.B., CH.B., F.F.A. R.C.S., D.A., D.oBST.R.C.O.G. ; JAMES WILLOCKS,* M.D., M.R.C.o.G.
}

Brit. med. F., 1967, 3, 396-400

British anaesthetists and obstetricians have made little use of epidural analgesia in obstetrics. From time to time small series have been reported by British workers who have used caudal or lumbar epidural analgesia in incoordinate uterine action (Galley, 1949 ; Johnson, 1952, 1954, 1957 ; Arthur and Johnson, 1952; Ball and Chambers, 1956 ; Tunstall, 1960) and in pre-eclampsia and eclampsia (Bryce-Smith and Williams, 1955 ; Scott, 1955).

In contrast, epidural techniques are extensively used for obstetric analgesia in many North American centres (Bush, 1959 ; Hingson et al., 1961 ; Hellmann, 1965 ; Moore, 1966) following on the pioneer work of Hingson and Edwards (1943). The reasons for this difference in practice are several.

Firstly, British obstetric opinion is generally in favour of encouraging spontaneous delivery where this can safely be achieved, and most spontaneous deliveries are conducted by midwives in hospital and at home. Epidural analgesia, because it produces perineal anaesthesia and so abolishes the reflex expulsive efforts of the second stage of labour, is usually associated with a high forceps delivery rate.

Secondly, epidural analgesia may be required at any time of the day or night, and its safe conduct necessitates the presence of an anaesthetist experienced in the technique for as long as the block is maintained. This demands a 24-hour obstetric anaesthetic service by experienced anaesthetists who are not committed to other duties. This service exists in few hospitals in Great Britain today, though in our experience the benefits are substantial and not confined to the administration of epidural analgesia.

Finally, there exist anaesthetists and obstetricians who believe, despite impressive evidence to the contrary, that epidural analgesia is a difficult and dangerous technique. With experience the success rate can approach $100 \%$, particularly in younger women without spinal deformities or the ossification of the supraspinous ligament which may develop in the elderly. The potential dangers of epidural analgesia should not be minimized, but with awareness of these dangers and constant attention to details in technique and management by a team of anaesthetists, obstetricians, and midwives the method is acceptably safe. The vast experience of others confirms this safety. Norris et al. (1960) reported over 9,000 epidural blocks in labour, and Hellmann (1965) reported over 26,000 cases. In neither series was there any foetal or maternal mortality attributable to epidural analgesia, and the incidence of complications was very low. Continuous observation is essential for safety, and an extra burden is thereby placed on nursing staff, who, in our experience, accept this willingly when convinced of the value of the procedure.

It is not our intention, however, to advocate the routine adoption of epidural analgesia for relief of pain in normal labour. In the Queen Mother's Hospital, Glasgow, continuous lumbar epidural analgesia is used in just over $4 \%$ of all labours and, in addition, " single-shot" epidural analgesia is used for $9 \%$ of mid-cavity forceps deliveries. During the last two and a half years 246 continuous epidural blocks have been given to patients in labour. In the 100 cases reported here the indication

* Queen Mother's Hospital, Glasgow C.3. was incoordinate uterine action. The present review was undertaken to assess the contribution made by epidural analgesia to the management of these cases.

\section{Anaesthetic Technique}

The lumbar rather than the caudal approach to the epidural space is preferred because of the higher success rate, the lower dose of local anaesthetic drug, and because the skin of the lumbar region seems less open to contamination than the skin over the sacral hiatus. The caudal approach is used when abnormalities of the lumbar spine are present.

Lumbar epidural puncture is performed with the patient in the sitting position to encourage spinal flexion, which may be difficult to achieve in the lateral position because of the gravid uterus. A 16 S.W.G. Tuohy needle is used and the epidural space is identified by the loss-of-resistance technique. A plastic catheter (Lee, 1962) with a blunt tip (Moir and Hesson, 1965) is then advanced into the epidural space, the needle is withdrawn, and the catheter is connected to a sterile plastic 50-ml. syringe filled with local anaesthetic solution. This syringe is now sealed inside a transparent bag (Cole, 1964) and strapped to the abdominal wall. This system allows top-up injections to be given without scrubbing-up and seems to avoid the risk of accidental overdosage associated with at least one of the drip techniques (Edmonds-Seal, 1964). Free mobility is permitted as there is no infusion apparatus connected to the patient.

The drug used is $2 \%$ lignocaine with $1: 200,000$ adrenaline added. Doses are varied slightly with maternal height and range from 6 to $9 \mathrm{ml}$. (120 to $180 \mathrm{mg}$.) of lignocaine. A larger dose of 10 to $12 \mathrm{ml}$. (200 to $240 \mathrm{mg}$.) is given before operative vaginal delivery to ensure perineal analgesia and relaxation of the pelvic floor muscles. The use of $2 \%$ lignocaine permits more injections to be made from the $50-\mathrm{ml}$. syringe than would be possible if weaker solutions were used. The percentage strength of lignocaine solution injected does not greatly influence the extent of analgesia obtained (Bromage, 1962).

Doses of lignocaine are kept as low as possible to minimize the risk of hypotension and because the free spread of solutions in the epidural space of the pregnant woman is recognized and probably attributable to engorgement of the epidural veins (Bromage, 1962). Prilocaine (Citanest) is not used, because repeated injections would be expected to produce considerable methaemoglobinaemia (Adamson and Spoerel, 1966).

\section{Complications}

The following complications were observed in the 100 cases reported here.

Dural Puncture.-This occurred in two patients. In one case the epidural catheter probably punctured the dura (Moir and Hesson, 1965) and spinal anaesthesia resulted. In the other case no injection was made. In neither case did mother or infant suffer harm.

Puncture of an Epidural Vein.-This was observed three times after passage of the catheter. No injection was made 
until the catheter had been displaced from the vein (in one case by repuncture at another interspace) and there were no harmful consequences.

Paravertebral Passage of the Catheter.-This occurred once. Only a narrow unilateral area of cutaneous anaesthesia developed and it was presumed that the catheter had passed out through an intervertebral foramen. Repeat puncture was satisfactory.

Toxic Effects of Lignocaine.-None was observed. The dose of lignocaine, with adrenaline, was always less than $250 \mathrm{mg}$. at each injection.

Hypotension.-Transient falls in systolic blood pressure to below $90 \mathrm{~mm}$. Hg were seen on 15 occasions in 100 epidural blocks in which almost 600 injections were given. This represents an incidence of about 2.5 per 100 injections. In 13 instances the hypotension responded immediately to turning the patient into the left lateral position and was attributed to the supine hypotensive syndrome. In the other two cases an intravenous injection of methoxamine $3 \mathrm{mg}$. restored normal blood pressure. This drug is better avoided because it can cause foetal bradycardia and tetanic uterine contraction (Vasicka et al., 1964) and constriction of uterine arteries (Greiss and Wilkes, 1964), and vasopressor drugs have not been used in our hospital during the last year.

Other Complications.-Retention of urine may, of course, complicate any labour, but is more likely to occur when bladder sensation is lost under epidural analgesia.

Lumbar-puncture headaches do not occur after epidural analgesia. No foetal or maternal mortality is attributable to the anaesthetic technique.

\section{Tachyphylaxis}

This has been discussed elsewhere (Moir and Willocks, 1966). We use this term to mean a substantial reduction in the duration of analgesia obtained after repeated injections of local anaesthetic drug. The phenomenon was seen in over $60 \%$ of cases where four or more top-up injections were required, and in $70 \%$ of these cases analgesia eventually lasted less than half as long as it had after the initial injection. This rather troublesome phenomenon is unexplained and has seldom been noted by others, though Bush (1959), Bromage et al. (1964), and Cox and Spoerel (1964) refer to it. Perhaps tachyphylaxis has been infrequently observed because epidural analgesia is not commonly given for the prolonged periods used in these incoordinate labours (average duration $10 \frac{1}{2}$ hours) where pain may be increasing rather than decreasing during the block.

\section{Description of Cases}

Continuous epidural analgesia was administered to 100 women with incoordinate labour in the Queen Mother's Hospital from March 1964 to July $1966-1.4 \%$ of the deliveries in that time.

In this highly selected group of abnormal cases conventional treatment had failed and the decision had to be taken whether to perform caesarean section without further prolongation of labour. Maternal distress and failure to respond to analgesic drugs, combined with incoordinate uterine action, were the criteria for the use of epidural analgesia. Incoordinate uterine action was a clinical diagnosis-contractions of varying frequency and strength which failed to dilate the cervix and bring the presenting part down in the normal way; most cases were of the hypertonic type associated with distressing pain and backache, but often hypertonic and hypotonic periods occurred in the same labour, as observed by Jeffcoate (1961). When periods of hypotonic uterine action were prominent an oxytocin drip was used : 29 patients had an oxytocin drip at some point after the institution of continuous epidural analgesia. As there was no consistent policy on the use of oxytocin, further comment on this aspect of treatment is difficult. Our impression is that in some cases a more liberal use of oxytocin would have been beneficial.

In a few cases the abnormal pattern of uterine contractions was confirmed by tocodynamometry.

On reviewing the cases thus selected we found that they exhibited many of the general features classically associated with incoordinate labour, such as short stature, postmaturity, large size of foetus, and occipitoposterior position (Table I). Ninetytwo of our patients were primigravidae; the remaining eight were in their second pregnancy and all of them had a history of prolonged labour, five having previously been delivered by caesarean section early in labour. Eighty-eight patients were under the age of 30 and none was over 35. Fifty-three patients had labour induced by rupture of the membranes, pre-eclampsia and postmaturity being the most common indications. The average duration of labour before the block was given was 23 hours. Vomiting, pyrexia, tachycardia, and ketonuria were common and intravenous glucose was freely used (Table II). When the membranes had been ruptured for more than 24 hours an antibiotic was given-usually ampicillin $500 \mathrm{mg}$. every six hours by intramuscular injection.

TABLE I.-Features Associated with Incoordinate Labour in This Series Primigravidae Age $<30$ years Height $<61$ in $\left(15 \dot{\mathrm{cm}} .{ }^{\cdots}\right.$ Gestation $>41$ weeks $(287$ days) Foetal weight $>8 \mathrm{lb}$. $(3.63 \mathrm{~kg}$.) Occipitoposterior position Surgical induction of labour (amniotomy)

TABLE II.-Physical Findings in 100 Patients with Incoordinate Uterine \begin{tabular}{lllllll}
\multicolumn{7}{c}{ Action } \\
Tachycardia (over 100/minute) \\
Pyrexia (over $37 \cdot 5^{\circ}$ C.)
\end{tabular}

The average duration of labour after epidural block was 10.2 hours and the average total duration of labour 33.25 hours.

\section{Effect of Epidural Block on Progress of Labour}

Epidural block was given only after the cervix was $4 \mathrm{~cm}$. dilated; once begun, analgesia was maintained continuously until delivery. Progress in labour was estimated by recording the frequency, duration, and intensity of uterine contractions by abdominal palpation and by assessing cervical dilatation by rectal and vaginal examination.

To obtain an objective assessment of the rate of progress in labour before and after epidural block we prepared, in retrospect, a graph or "partogram" (Rodesch et al., 1965) for each of our cases, employing the method of Friedman (1955), who has made extensive studies of the graphic analysis of labour (Friedman, 1954, 1956 ; Friedman and Sachtleben, 1961a, 1961b, 1962a, 1962b, 1963a, 1963b, 1965). Friedman assesses progress of labour by graphing cervical dilatation against time because "the dilatation of the cervix is the result of all the driving force of uterine contractions acting upon the uterine contents and against the resistance of the maternal soft parts," and thus is the best index of progress in labour (Friedman, 1965). In the normal primigravida, Friedman (1955) has shown that cervical dilatation in the "active phase" of the first stage of labour (after $3 \mathrm{~cm}$.) progresses in an almost linear fashion.

In our cases we compared (a) the rate of cervical dilatation in the time from $3 \mathrm{~cm}$. (when the "active phase" usually begins) until the epidural block was given with (b) the rate from epidural block until delivery. We avoided any comparison which included the "latent phase" before $3 \mathrm{~cm}$. dilatation, as 
this would have given a false impression of an increased rate of dilatation after epidural block. In all cases the records of vaginal rather than rectal examinations were used to construct the graphs.

In three cases there was insufficient information to make a calculation, but the results for 97 cases were that the rate of dilatation after epidural block was increased by at least one and a half times in 68 cases $(70 \%)$. Dilatation proceeded at an unchanged rate in 18 cases (18.6\%) and was slowed in 11 cases $(11.3 \%$ ) (see Table III).

TABLE III.-Rate of Cervical Dilatation After Epidural Block in 97 Cases

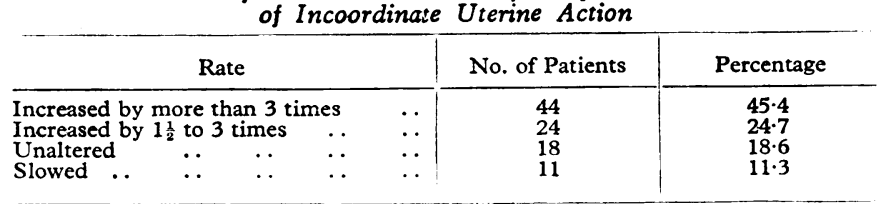

As has already been pointed out, only a minority of patients had oxytocin drips, usually for short periods, and there was no consistent policy on the use of oxytocin. The response of the uterus to epidural block did not seem to be related to the use of oxytocin.

The method of delivery is shown in Table IV. Caesarean section was performed in 26 cases: five of these had already reached the second stage of labour and an attempt at vaginal delivery had failed because of mechanical difficulty, while in another two cases an attempt at vaginal delivery was thought inadvisable though the cervix was almost fully dilated. The findings regarding progress in labour and eventual method of delivery should be interpreted in the light of the presence or absence of cephalopelvic disproportion.

TABLE IV.-Method of Delivery in 100 Cases of Incoordinate Uterine Action Treated by Epidural Block \begin{tabular}{lllll|l} 
Cacsarean section & $\ldots$ & $\ldots$ & 26 & Vacuum extraction \\
F orceps &. & $\ldots$ & $\ldots$ & 48 & Spontaneous
\end{tabular}

\section{Effect of Cephalopelvic Disproportion on Results}

Glasgow was at one time notorious for its high incidence of contracted pelvis, and dystocia from this cause is still commoner than in most areas in the United Kingdom, though severe and obvious pelvic contraction such as that caused by rickets is now seldom seen and the diagnosis of cephalopelvic disproportion is often made only in labour or at delivery. Antenatal examination had already excluded major degrees of contracted pelvis in the patients of this series, but in 29 cases it was found that disproportion, usually associated with malposition of the foetal head (particularly occipitoposterior), caused appreciable mechanical difficulty in labour or at delivery.

Jeffcoate (1965) reiterated that small women with large babies are liable to have incoordinate labours. Forty of our patients were $61 \mathrm{in} .(155 \mathrm{~cm}$.) or less in height: disproportion was present in $16(40 \%)$ of these and 10 of the 16 babies weighed $8 \mathrm{lb}$. $(3.63 \mathrm{~kg}$.) or more, while in the remaining 24 short women ( $60 \%$ of the group) disproportion was not present though 10 of the babies weighed more than $8 \mathrm{lb}$. (3.63 kg.).

There were 60 patients whose height was more than 61 in. $(155 \mathrm{~cm}$.). Disproportion was present in $13(22 \%)$ of these, and 8 of the 13 babies weighed more than $8 \mathrm{lb}$. ( $3.63 \mathrm{~kg}$.), while in the remaining $47(78.3 \%$ of the taller group) there was no disproportion and 21 of the 47 babies weighed more than $8 \mathrm{lb}$. (3.63 kg.).

The rate of cervical dilatation before and after epidural block in cases with and without cephalopelvic disproportion is shown in Table V, from which it appears that disproportion did not significantly alter the improvement in uterine action in response to epidural block.
In contrast Table VI shows that disproportion was the most important factor influencing the method of delivery, the caesarean section rate being $55.2 \%$ in cases with, and $14.1 \%$ in cases without disproportion.

\begin{tabular}{|c|c|c|}
\hline Rate & $\begin{array}{c}70 \text { Cases Without } \\
\text { Disproportion }\end{array}$ & $\begin{array}{l}\text { 27 Cases With } \\
\text { Disproportion }\end{array}$ \\
\hline $\begin{array}{l}\text { Increased by more than } 3 \text { times } \\
\text { Increased by } 1 \frac{1}{2} \text { to } 3 \text { times } \\
\text { Unaltered } \\
\text { Slowed }\end{array}$ & $\begin{array}{r}34(48 \cdot 6 \%) \\
18(25 \cdot 7 \%) \\
12(17 \cdot 1 \%) \\
6(8.6 \%)\end{array}$ & $\begin{array}{c}10(37 \cdot 0 \%) \\
6(22 \cdot 2 \%) \\
6(22.2 \%) \\
5(18.6 \%)\end{array}$ \\
\hline
\end{tabular}

TABLE VI.-Method of Delivery in 100 Cases of Incoordinate Uterine Action Divided According to Presence of Disproportion

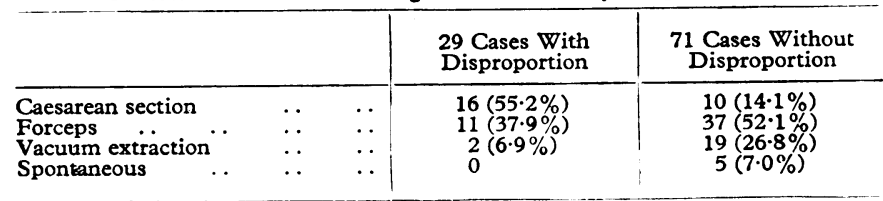

When an increased rate of dilatation followed epidural block in cases with disproportion the caesarean section rate was $27.6 \%$, whereas if the rate of dilatation was increased and no disproportion was present the caesarean section rate was only $3.8 \%$.

\section{Blood Loss at Delivery under Epidural Block}

The average blood loss, recorded accurately by a haemoglobin-dilution technique, at forceps delivery in 33 of our cases was $371 \mathrm{ml}$. Only $2(6 \%)$ of these patients lost more than 500 $\mathrm{ml}$. These figures compare favourably with blood loss at forceps deliveries under general anaesthesia (where the average loss was $412 \mathrm{ml}$. and the incidence of postpartum haemorrhage was $29 \%$ ) (Moir and Wallace, 1967).

It is our impression that the principal source of bleeding at delivery under epidural block is the episiotomy rather than the placental site and that uterine retraction is excellent. There is no evidence that the management of incoordinate labour under epidural analgesia predisposes to postpartum haemorrhage.

\section{Foetal Mortality and Morbidity}

There was one stillbirth and one neonatal death in the series, giving a perinatal mortality of $2 \%$. An account of these deaths is given in the discussion.

The Apgar score of the 99 liveborn babies was estimated two minutes after birth. Sixty-six babies $(66.6 \%)$ had a score of 7 or over. Seventeen babies $(17.1 \%)$ had a score of 4 or less. The number requiring active resuscitation (by intubation or hyperbaric oxygenation) was 15 . There were three cases of intrauterine pneumonia or meconium aspiration syndrome and three cases of transient cerebral irritation. No other serious complications occurred and all 98 surviving babies were dismissed apparently well.

\section{Maternal Morbidity}

The stay of the mothers in hospital after delivery was of normal duration.

Puerperal pyrexia of $37.6^{\circ}$ C. $\left(99.7^{\circ}\right.$ F.) or over occurred transiently in 24 patients. One patient was readmitted two weeks after delivery with a genital infection. 


\section{Discussion}

One hundred women were given continuous epidural analgesia because they were having painful incoordinate labours. Review of these cases showed a high incidence of young primigravidae, short maternal stature, large foetal size, and occipitoposterior position (Table I).

Twenty-nine patients had appreciable mechanical difficulty in labour or at delivery because of minor degrees of disproportion, often in association with occipitoposterior position. Mechanical difficulty of this kind has proved to be the most important factor influencing the method of delivery, and if such cases could be excluded treatment would be much simplified and the results would be better. Experience with this series, however, has confirmed our belief that it is suldom possible to predict mechanical difficulty in labour by antenatal examination except in gross cases of disproportion. The position and attitude of the foetal head are important, but in the borderline case it is the action of the uterus which is the most important factor, and in the primigravida this is completely unknown until labour begins. Often it is only after labour is far advanced that the mechanical problem becomes evident; if pain is abolished by epidural block there is usually nothing to lose by waiting until the diagnosis is clear.

With relief of pain, the patient's general condition may be improved out of recognition, but the obstetrician should always remember the dangers of disproportion and should not strive too zealously for a vaginal delivery. Even "trial of forceps" with the theatre set for caesarean section is not always a safeguard, as the following case illustrates.

A primigravida aged 27 had an incoordinate first stage of labour lasting $45 \frac{1}{2}$ hours, the last 20 hours being managed under epidural analgesia. After an hour in the second stage a trial of vaginal delivery was attempted. The vacuum extractor was applied without success and rotation and traction with Kielland's forceps produced no advance. For the first time disproportion was now detected. Caesarean section was performed and the child (weight $3.9 \mathrm{~kg}$.) died five hours later of intracranial haemorrhage from tentorial tears.

When the fault in labour is principally one of uterine action epidural analgesia helps considerably in allowing labour to continue painlessly and with a likelihood of improving uterine action until the second stage is reached, and there is a low caesarean section rate in such cases. It is difficult to assess whether epidural block has a stimulating effect on the progress of labour, even though a graphic analysis showed an increased rate of dilatation in $70 \%$ of cases, for some patients also had oxytocin drips and all had dehydration and acidosis corrected as required. Both clinical experience and in-vitro evidence (Mark, 1961) suggest that acidosis impairs uterine action.

Two infants have been lost. One, already described, died from intracranial haemorrhage. The details of the other case are as follows:

A primigravida aged 23 had lajour induced at $41 \frac{1}{2}$ weeks. She had a hypertonic incoordinate labour (with marked dehydration, acidosis, and bowel distension) for 28 hours, when epidural analgesia was induced. Two isours later the foetal heart was not heard. At no time was maternal hypotension detected and there was no warning irregularity of the foetal heart or meconium staining. A stillborn child was delivered 19 hours later with considerable difficulty, the vacuum extractor being used as the cervix was not yet fully dilated. This case illustrates the need for greater information about the condition of the child in utero, particularly when labour is prolonged. Few other patients in our series have had perhaps an equally unsuitable environment for the baby.

The perinatal mortality rate for the hospital is $3.8 \%$. The present series is small and a foetal loss of $2 \%$ is probably acceptable for those difficult cases, but it must be remembered that few premature babies were included. Comparable figures for foetal loss are $2.5 \%$ for labours lasting more than 24 hours (Royal Maternity Hospital, Belfast, 1963), $4.1 \%$ for labours longer than 30 hours (National Maternity Hospital, Dublin,
1964), and $7.6 \%$ for labours longer than 48 hours (Glasgow Royal Maternity Hospital, 1962). Separate figures for incoordinate labour are difficult to obtain, as this does not usually appear as an entity in hospital reports.

The acceptable condition of most infants in the series is shown by the Apgar scores and the low incidence of serious complications already quoted.

It is unnecessary to give depressant analgesic drugs to patients under epidural block, and this means that the child is more easily stimulated to take his first breath.

The value of antibiotic treatment in preventing the child becoming infected in utero is not precisely known, but further studies will probably soon elucidate this. Ampicillin, which is prubably the most effective drug for the purpose (Williams and Felton, 1966 ; Blecher et al., 1966), was used when the membranes had been ruptured more than 24 hours or when there was pyrexia.

The obstetric policy in this series has been conservative, as is indicated by a caesarean section rate of $26 \%$, but there is no doubt that good results have been obtained in many places by a much wider use of caesarean section. The radical attitude adopted now in some centres is illustrated by the figures from the Royal Maternity Hospital, Belfast (1963), where the caesarean section rate for cases of abnormal uterine action without disproportion was $80 \%$, there being no foetal loss, and the caesarean section rate for cases of contracted pelvis was $91.8 \%$, the foetal loss being $2 \%$.

It is our opinion that such a high caesarean section rate is not justified for incoordinate labour in the young primigravida because the uterine dysfunction is unlikely to recur in a subsequent labour if the cervix reaches at least half dilatation in the first labour (Jeffcoate et al., 1952 ; Jeffcoate, 1961). In the older patient earlier resort to caesarean section is, of course, justified. The woman who has once been delivered by caesarean section faces a risk at subsequent confinements, whether or not a policy of repeat section is followed. Caesarean section is not always the easy and atraumatic operation that it ideally should be, and the postoperative complications are not negligible, the risk of thromboembolism, for example, being nearly six times greater than after vaginal delivery (Claye, 1961).

Incoordinate labour is often terminated by caesarean section because of maternal distress. Our object in using epidural analgesia has been to abolish pain so that time is available for the problem to be resolved to the extent that the woman either has a safe vaginal delivery or is delivered by caesarean section after the cervix is at least half dilated. When the patient has been completely relieved from pain the obstetrician can review the case more calmly; he may then reflect on the maxim of William Smellie (1752) that "it takes more skill to prevent than to perform an operation."

There is no doubt that the method demands both time and skill from a team of obstetricians, anaesthetists, and midwives.

Of the value of epidural analgesia in the management of incoordinate labour we are entirely convinced. Looking back on the patients whose records we have presented here, we regret that the treatment was applied so late to many of them, but the method was a new one in the hospital and only the most difficult cases were chosen for this series. Few who have seen the transformation epidural analgesia brings to a woman distressed with an incoordinate first stage can fail to welcome it with enthusiasm.

Incoordinate labour remains a major problem in modern obstetric practice. Caesarean section cuts across the problem but does not provide an answer to it. The ideal solution would be to achieve complete control over uterine function and complete pain relief at the same time. We do not claim that epidural analgesia does this, but it is a step towards the ideal. 


\section{Summary}

One hundred women with incoordinate uterine action had labour managed under continuous epidural analgesia, the average duration of the block being 10 hours. Most of the patients were primigravidae, many were of small stature, and many had large babies, commonly with the occiput in the posterior position. Graphic analysis of labour showed an increased rate of cervical dilatation after epidural block in over $70 \%$. The caesarean section rate remained high $(55 \%)$ in cases complicated by mechanical dystocia, but where this was not present the caesarean section rate was much lower (14\%), while in those patients who had no cephalopelvic disproportion and who showed an increased rate of dilatation after epidural block the caesarean section rate was only $3.8 \%$. With this management, caesarean section is rarely required purely for incoordinate uterine action or maternal distress.

The perinatal mortality in the series was $2 \%$, and there were no serious maternal complications.

Dr. John MacVicar provided the initial stimulus for this work, and our thanks are due to him and to Professor Ian Donald for continued encouragement and help. The work could not have been done without the untiring efforts of the labour room staff, whose cheerful co-operation was much appreciated.

\section{REFERENCES}

Adamson, D. H., and Spoerel, W. E. (1966). Acta anaesth. scand., Suppl. No. 23 , p. 379.

Arthur, H. R., and Jahnson, G. T. (1952). \}. Obstet. Gynaec. Brit. Emp., 59,372 .

Ball, H C. J., and Chambers, J. S. W. (1956). Brit. med. F., 1, 1275.

Blecher, T. E., Edgar, W. M., Melville, H. A. H., and Peel, K. R. (1966). Ibid., 1, 137 .

Bromage, P. R. (1962), Brit. F. Anaesth., 34, 161.

Bromage, P. R. (1962), Brit. F. Anaesth., 34, 161. Ibid., 36, 342.

Bryce-Smith, R., and Williams, E. O. (1955). Lancet, 1, 1241.

Bush, R. C. (1959). Anesthesiology, 20, 31.

Claye, A. (1961). f. Obstet. Gynaec. Brit. Cwlth, 68, 577.
Cole, P. V. (1964). Anaesthesia, 19, 562.

Cox, J. M. R., and Spoerel, W. E. (1964). Canad. Anaesth Soc. F., 11, 72 Edmonds-Seal, J. (1964). Anaesthesia, 19, 222.

Friedman, E. A. (1954). Amer. F. Obstet. Gynec., 68, 1568.

- (1955). Obstet. and Gynec., 6, 567.

- (1956). Ibid., 8, 691.

(1965). In Obstetrics, 13th ed., by J. P. Greenhill, p. 832. Philadelphia and London.

- and Sachtleben, M. R. (1961a). Obstet. and Gynec., 17, 135.

- - (1961b). Ibid., 17, 566 .

- (1962a). Ibid., 19, 576.

- (1962b). Ibid., 20, 761.

- (1963a). Ibid., 21, 13.

- (1963b). Ibid., 22, 478 .

Galley, A. H. (1949). Anaesthesia, 4, 154.

Galley, A. H. (1949). Anaesthesia, 4, 154.

Glasgow Royal Maternity Hospital (1962). Clinical Report.

Greiss, F. C., and Wilkes, D. V. (1964). Obstet. and Gynec., 23, 925.

Hellmann, K. (1965). Canad. Anaesth. Soc. F., 12, 398.

Hingson, R. A., Cull, W. A., and Benzinger, M (1961) Anaesth. Analg. Curr. Res., 40, 119.

and Edwards, W. B. (1943). f. Amer. med. Ass., 121, 225.

effcoate, T. N. A. (1961). Lancet, 2, 61.

- (1965). Aust. N.Z.F. Obstet. Gynaec., 5, 222.

Baker, K., and Martin, R. H. (1952). Surg. Gynec. Obstet., 95,

Johnson, G. T. (1952). 7. Obstet. Gynaec. Brit. Emp., 59, 644.

- (1954). Brit. med. F., 1, 627.

(1957). Ibid., 2, 386.

Lee, J. A. (1962). Anaeshesia, 17, 248.

Mark, R. F. (1961). 7. Obstet. Gynaec. Brit. Cwlth, 68, 584.

Moir, D. D., and Hesson, W R (1965) Anaesthesia, 20, 373

- and Wallace, G. (1967). In press.

- and Willocks, J. (1966). Acta anaesth. scand., Suppl. No. 23, p. 144.

Moore, D. C. (1966). In discussion on obstetric anaesthesia at the Second European Congress of Anaesthesiology.

National Maternity Hospital, Dublin (1964). Clinical Report.

Norris, S., Harris, L. J., and Eisen, S. M. (1960). Obstet. and Gynec. 16, 15 .

Rodesch, F., Ehman-Ellinger, C., Wilkin, P., and Hubinont, P. O. (1965). f. Obset. Gynaec. Brit. Cwilth, 72, 930 .

Royal Maternity Hospital, Belfast (1963). Clinical Report.

Scott, D. B. (1955). Lancet, 2, 43.

Smellie, W. (1752). Treatise on the Theory and Practice of Midwifery

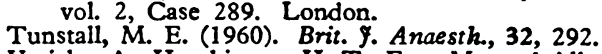

Vasicka, A., Hutchinson, H. T., Eng, M., and Allen, C. R. (1964). Amer 9. Obstet. Gynec., 90, 800 .

Williams, J. D., and Felton, D. J. C. (1966). 7. Obstet Gynaec. Brit. Cwlth., 73, 654.

\title{
Value of Rectal Biopsy in Paediatric Neurology: Report of 165 Biopsies
}

\author{
E. M. BRETT,* D.M., M.R.C.P. ; C. L. BERRY, † M.B., B.S.
}

Biopsy of neural tissue, with subsequent histopathological, chemical, and histochemical examination, plays an important part in the investigation of suspected degenerative disease of the central nervous system in infancy and childhood. For a number of reasons brain biopsy is not always acceptable to parent or clinician.

The possibility of using rectal biopsy as a diagnostic test for progressive degenerative brain disease seems to have been first suggested by the necropsy observation of Globus (1942), who noted similar degenerative changes in neurones of the central nervous system and of the myenteric plexus in a case of amaurotic idiocy. Landing and Freiman (1957) encountered similar necropsy findings in various forms of amaurotic idiocy, Niemann-Pick's disease and Hurler's syndrome; and Nakai and Landing (1960) suggested that rectal biopsy might be used in the diagnosis of neurolipidosis. Kobayashi (1960) proposed the use of biopsy of the rectal wall or appendicectomy for the histochemical demonstration of "the dystrophic deposit in

\footnotetext{
- Senior Registrar in Nearology, the National Hospital for Nervous Diseases, Queen Square, and Department of Neurology, Hospital for Diseases, Queen Square, and Department of Neurology,

t Lecturer in Morbid Anatomy, the Institute of Child Health, London W.C.1.
}

ganglion cells of the myenteric plexus" in gargoylism. A series of 75 rectal biopsies was reported by Martin, Landing, and Nakai (1963), but many of these were from patients with suspected Hirschsprung's disease or were incidental to operations for imperforate anus, and only 11 seem to have been intended primarily to further the neurological diagnosis. No specific neurological diagnoses were reached as a result of these biopsies, but the authors believed that rectal biopsy might be as reliable as brain biopsy in the neural lipidoses, and that it should probably be considered in the diagnostic investigation of any otherwise unexplained degenerative neurological disorder of childhood.

Bodian and Lake (1963) reviewed 21 necropstes in which complete agreement was found between neuronal changes in the central nervous system and in the gastrointestinal tract, and there was also evidence of metachromasia in the latter if present in the brain. They further reported a series of 49 rectal biopsies based on this study ; 26 of these were normal and 23 showed abnormalities. The latter included 12 cases with changes regarded as non-specific, and 11 with diagnostic features (seven cases of neurolipidosis and four of metachromatic leucodystrophy. The authors suggested that this 